\title{
PERCEPÇÃO DE RISCO NA INTERNACIONALIZAÇÃO DE EMPRESAS FAMILIARES
}

\author{
Isabella Spengler \& ${ }^{1}$ Dinorá Eliete Floriani \\ Hof University of Applied Sciences, (Alemanha) \\ Universidade do Vale do Itajaí - UNIVALI, Santa Catarina, (Brasil)
}

DETALHES DO ARTIGO
Histórico do Artigo:
Recebido em: 15 de setembro de 2020
Aceito: 07 de setembro de 2021
Disponível online: 12 de novembro de
2021
Sistema de revisão "Double blind review"
Editor Científico
Ilan Avrichir

\section{Palavras-chaves:}

Internacionalização

Empresa Familiar

Percepção de Risco

\begin{abstract}
RESUMO
Objetivo: O estudo tem como objetivo compreender como a percepção de risco afeta o processo de internacionalização em empresas familiares.

Método: O presente artigo apresenta uma abordagem qualitativa e se utiliza da estratégia de estudo de caso. Foram realizadas entrevistas semiestruturadas com gestores familiares e não-familiares de duas empresas familiares.

Principais resultados: Identifica-se convergência entre os modelos teóricos e empíricos com a complementariedade de duas novas categorias de análise no modelo empírico, objetivos estratégicos e operacionalização por não familiar, que influenciam na relação e podem resultar em maior ou menor grau de internacionalização.
\end{abstract}

Relevância/originalidade: A percepção de risco é um importante aspecto na internacionalização de empresas familiares de países emergentes e se faz necessário intensificar estudos que analisem seus efeitos nas estratégias internacionais. O presente estudo apresenta a influência de duas categorias que se mostraram relevantes ao processo de internacionalização de EFs, além dos efeitos já verificados na literatura, os objetivos estratégicos e operacionalização por não familiar.

Contribuições teóricas/metodológicas: Este estudo contribui com a inserção dos objetivos estratégicos e a presença de um gestor externo à família frente à internacionalização que atenuam a percepção de risco e contribuem para estratégias de maior envolvimento internacional. Quando constatado a familiness entre os gestores dos casos estudados, percebeu-se uma capacidade dos mesmos transferirem este valor para membros nãofamiliares. Esses aspectos podem se tornar uma barreira para a internacionalização. Por outro lado, as empresas familiares podem, por meio das conexões estabelecidas, reavaliar suas estratégias a fim de se obter melhores resultados na internacionalização.

\section{Introdução}

As empresas familiares (EFs) são de extrema importância para o crescimento econômico e a forma mais comum de organização em países emergentes (Basco, 2018; Panicker et al., 2019).As EFs são controladas por membros da mesma família ou por um pequeno número de famílias que se preocupam em manter a visão do negócio (Chua, Chrisman \& Sharma, 1999) e a reputação da firma (Odom, Chang, Chrisman, Sharma \& Steier, 2019). Embora essas empresas não busquem ganhos imediatos, priorizando os planos futuros (Álvares, 2003; Kretinin, Samuel \& Kashyap, 2019), enfrentam desafios como resistência a mudanças e processo de sucessão, que podem acarretar em uma ruptura nos negócios (Gallo \& Pont, 1996; Centeno-Caffarena \& Bocatto, 2006).

No Brasil, estima-se que apenas $12 \%$ dos empreendimentos familiares chegam a terceira geração e apenas $3 \%$ a quarta (PricewaterhouseCoopers [PwC], 2017). As EFs brasileiras estão menos orientadas para a expansão internacional do que a média global deste segmento. As exportações brasileiras de EFs representam apenas $8 \%$ do volume de vendas; enquanto no mundo, obtêm aproximadamente um quarto de suas vendas no exterior (PwC, 2017). 
Ainda que a literatura apresente resultados mistos sobre a propriedade familiar e a internacionalização (Kontinen, 2011; De Massis, Frattini, Majocchi \& Piscitello, 2018; Manogna et. al., 2020), a principal linha de pesquisa expõe que as EFs se arriscam menos em suas estratégias no exterior, tendo em vista a sobrevivência da empresa ao longo das gerações e manutenção do patrimônio familiar (familiness). Porém, é importante destacar que estes estudos se deram majoritariamente nos Estados Unidos e na Europa (Odom et al., 2019), podendo não ser aplicados a EFs de países emergentes (Basco, 2018). Além de outras variações internas e externas do contexto em que as EFs estão inseridas (Eddleston et. al., 2018), como diferenças institucionais e do período de aplicação de pesquisa (Manogna et. al., 2020).

Desta forma, faz-se necessário o avanço dos estudos entre os negócios internacionais e EFs (De Massis et al., 2018; Manogna et. al., 2020), especialmente no que tange à percepção de risco e sua influência no processo de internacionalização dessas empresas (Dou, Jacoby, Li, Su \& Wu, 2019; Santulli, Torchia, Calabro \& Galucci, 2019). A presente pesquisa busca compreender como a percepção de risco afeta o processo de internacionalização em EFs, adotando como caso de análise empresas de mercado emergente, o Brasil. Por meio de uma pesquisa qualitativa, entrevistas semiestruturadas foram realizadas em duas EFs, com gestores familiares e não-familiares. Após elaboração do framework teórico, os dados foram analisados por meio de análise de conteúdo e elaborou-se um modelo empírico com base nos resultados obtidos.

Esta pesquisa contribui com a literatura de Internacionalização de EFs discutindo dois fatores, a definição de objetivos estratégicos da internacionalização da EF e a presença de um profissional externo à família. Ambos os fatores podem atenuar o efeito da percepção de risco na internacionalização de EFs, contribuindo para estratégias de maior comprometimento internacional. 0 artigo apresenta, além desta introdução, o aporte teórico que possibilitou o desenvolvimento de um framework teórico e o método com detalhes da elaboração da pesquisa. Em seguida, a análise dos dados, apresentando o modelo empírico e as proposições, e, por fim, a conclusão.

\section{Fundamentação teórica}

\subsection{Internacionalização de EFs e a percepção do risco}

Embora a internacionalização de EFs possibilite o crescimento contínuo dos negócios (De Massis et al., 2018) e maior rentabilidade para a firma (Zahra, 2018), também pode gerar conflitos internos (Zahra, 2003). Assim, a internacionalização pode ser positivamente e/ou negativamente afetada pela gestão familiar (De Massis et al., 2018; Zahra, 2018; Kretinin et al., 2019; Sánchez-Marín, Pemartín \& Monreal-Pérez, 2020). As diferentes formas no processo de internacionalização dependem de características de propriedade, como a propriedade familiar, e o ambiente institucional, como o contexto institucional de economias emergentes (Panicker et al., 2019).

Os estudos sobre internacionalização de empresas familiares contrapõem duas linhas principais, uma visão restritiva/gradual e outra facilitadora/acelerada (Arregle \& Hitt \& Mari, 2019). A primeira destaca a percepção de risco e comportamento conservador, fruto de tradição e forte envolvimento da família nos negócios (CentenoCaffarena \& Bocatto, 2006; Gomez-Mejia \& Makri; Kintana, 2010; Denicolai et. al, 2019). Já a outra, expõe a capacidade de se reinventar em períodos de dificuldade econômica, aliada a uma postura empreendedora e dinâmica (Monticelli, 2018; Zahra; 2018).

Em se tratando da perspectiva restritiva, a percepção de risco entre os gestores de empresas familiares é decisiva para diversas etapas da internacionalização, entre elas a escolha de mercados. Este entendimento reflete na expansão das firmas a mercados internacionais, que por vezes são relutantes quando identificado alto grau de incerteza.

A aceitação ao risco demonstra ser um dos principais fatores a ser estudado entre empresas familiares, especialmente em âmbito internacional. Zahra (2018) e Lude e Prügl (2019) expõem a necessidade de conhecer a real conexão entre a participação familiar e a tomada de decisão no comércio internacional. Magnani, Zucchella e Floriani (2018) também defendem que as estratégias destas firmas são influenciadas pelas distâncias culturais, geográficas e institucionais existentes entre o país de origem e o destino. 
Além da exposição ao risco e falta de recursos financeiros, a ameaça ao controle interno pode inibir a internacionalização dessas empresas (Kontinen, 2011; Eddleston et. al., 2018). No entanto, após o ingresso em mercado estrangeiro, a EF tende a se expandir e aumentar seu comprometimento de forma relativamente acelerada (Kretinin et al., 2019). Apesar de EFs se internacionalizarem mais tarde do que empresas não-familiares, esta relação não é refletida ao longo do tempo, visto que ao iniciar o processo de internacionalização, não há diferenças significativas entre as firmas (Graves \& Thomas, 2004). Monticelli (2018) acrescenta ainda, que a tradição familiar das firmas acarreta em um comportamento conservador em termos de estratégias internacionais.

Percebe-se, assim, que a principal dificuldade de EFs encontra-se nas fases iniciais da internacionalização (Centeno-Caffarena \& Bocatto, 2006), em que as empresas apresentam resistência a profissionais externos à família para cargos de gestão e direção, bem como a redes de relacionamentos internacionais (Graves \& Thomas, 2006). No processo de internacionalização a EF preocupa-se então em manter o controle sobre seu negócio (Gomez-Mejia, Makri \& Kintana, 2010; Kretinin et al., 2019), consequentemente, tende a se expandir para mercados mais próximos, resultando em um escopo menor de internacionalização (Massis et al., 2018).

Nesse sentido, um dos principais aspectos para a atratividade de uma determinada região são as distâncias existentes entre a localidade de origem e a de destino, sejam elas cultural, geográfica, institucional ou psíquica (Magnani, Zucchella \& Floriani, 2018; Kretinin et al., 2019). A distância geográfica refere-se ao distanciamento em quilômetros entre países, o que pode ser considerado uma barreira frente ao comércio exterior, visto o alto custo de transporte e lead time embutidos (Hutzschenreuter, Kleindienst \& Langue, 2015; Hernández, Nieto \& Boellis, 2017), bem como ao menor controle sob as operações estrangeiras (Kretinin et al., 2019).

Já a cultural relaciona-se com a etnia, idioma, religião e normas sociais nacionais dos países. Um índice mais alto de distanciamento cultural representa maiores obstáculos para a internacionalização de empresas (Kretinin et al., 2019), enquanto a similaridade das culturas facilita a relação comercial e torna-se um motivador para o investimento estrangeiro (Ferreira \& Falcão, 2019).

A institucional, por sua vez, regula atividades econômicas entre países e pode resultar tanto em oportunidades quanto em desafios para a internacionalização de empresas (Ferreira \& Falcão, 2019). Para Hernández et al. (2017) as firmas são mais propensas a entrar em um mercado com distância institucional positiva, isto é, aquele com grau institucional mais elevado em relação ao de origem, por proporcionar um ambiente mais seguro. Já para Ferreira e Falcão (2019), um maior distanciamento institucional entre dois países indica incertezas e riscos no processo e, consequentemente, menor índice de investimento direto estrangeiro (IDE). EFs eventualmente se beneficiam de lacunas institucionais em economias emergentes, como apoio governamental e ausência de sistemas regulatórios estruturados (Panicker et al., 2019; Manogma et. al., 2020), vantagem a qual não é transferida a mercados internacionais e pode influenciar negativamente a internacionalização (Panicker et al., 2019).

Ainda, no que tange à distância psíquica, a internacionalização é entendida como um processo gradativo e incremental, em que as empresas optam por iniciar suas operações no exterior em mercados com menor distância psíquica, e à medida que adquirem experiência, aumentam seu grau de comprometimento (Johanson \& Vahlne, 1977). No entanto, Magnani et al. (2018) expõem que a característica de aproximação gradual não é validada. Os autores defendem que outros aspectos, como a própria estratégia organizacional e natureza do negócio, desempenham papel fundamental na seleção do mercado estrangeiro, podendo superar a perspectiva da distância psíquica.

A gestão familiar resulta em um processo de tomada de decisão mais rápido e claro (Santulli et al. 2019), em que a estratégia de internacionalização pode aumentar o mercado de abrangência da EF e incentivar a exploração de oportunidades no mercado internacional (Sánchez-Marín et al. 2020). Zahra (2018) defende que EFs não são conservadoras, dada a capacidade de se reinventar ao enfrentar mudanças econômicas, utilizando-se de ações inovadoras e investindo em pesquisa. Segundo o autor, a tomada de riscos por parte dos empreendedores é uma importante característica na EF e isto se comprova ao identificar que várias das 
empresas mais bem-sucedidas no mundo são de origem familiar.

No entanto, embora a orientação em longo prazo dessas empresas pode tornar-se uma aliada na estratégia internacional, fortalecendo o comprometimento e planejamento da organização (Gallo \& Pont, 1996; Denicolai et al., 2019), também pode refletir que os gestores familiares buscam a sobrevivência da empresa entre as gerações e se submetem a menores riscos em suas estratégias (Lude \& Prügl, 2019). A medida em que as firmas obtêm sucesso nos negócios, a sensibilidade ao risco se acentua, já que buscam proteger o patrimônio e riqueza acumulada (Zahra, 2018). Porém, se em um cenário positivo evitam decisões estratégicas arriscadas, em um momento desfavorável e de crise, tendem a aceitar níveis mais altos de risco, buscando recuperação do negócio (Lude \& Prügl, 2019).

\subsection{Familiness e propriedade na Internacionalização}

As categorias de análise familiness e propriedade dizem respeito às características das empresas em se tratando da relação familiar. Ambas influenciam a percepção de risco, a qual se relaciona com a resistência à mudança, aversão a recursos externos e visam constante preservação do patrimônio familiar (Gallo \& Pont, 1996; Graves \& Thomas, 2004; Centeno-Caffarena \& Bocatto, 2006; Goede, Floriani \& Furtado, 2017).

Familiness é citado na literatura como "envolvimento da família" e "efeito familiar", considerado a característica que simboliza a influência da família nas organizações e diz respeito à essência e identidade de EFs (Süss \& WeismeierSammer, 2013; Cano-Rubio, Fuentes-Lombardo, Hernandez-Ortiz, Vallejo-Martos, 2016). Representa um senso de pertencimento do negócio para com a família, e vice-versa, que o faz ser único e inimitável por competidores, podendo se tornar uma vantagem competitiva para EFs (Basco, 2018).

Para Habbershon e Williams (1999), familiness é definido como um conjunto de recursos que são distintivos de uma empresa, em função do envolvimento entre os membros da família e o negócio. Para os autores, o efeito familiar cria recursos de relevância para a empresa, que melhoram seu desempenho e resultam em vantagem competitiva. O desempenho mais bem-sucedido é refletido tanto em questões econômicas quanto não econômicas, tendo em vista que preserva laços familiares e busca a continuidade da empresa no longo prazo (Pearson, Carr \& Shaw, 2008).

Enquanto a visão pioneira defende uma perspectiva de recursos distintivos, Pearson et al. (2008) defendem que o familiness deve ser estudado sob um viés social, indicando antecedentes que são propícios para o desenvolvimento de recursos comportamentais e sociais e que agregam valor à empresa. Para Frank, Kessler, Rusch, Suess-Reyes, Weismeier-Sammer (2016), EFs são sistemas sociais, pois unem negócios e famílias. O sistema é influenciado por expectativas da família e por premissas de decisão, isto é, informações/padrões essenciais que moldam decisões e comportamentos nos negócios de acordo com as expectativas dos membros da família. Assim, para os autores, familiness deve ser mensurada por meio de três principais dimensões: envolvimento da família, essência da influência familiar e identidade organizacional.

Em se tratando de seus resultados, Daspit, Long e Pearson (2019) argumentam que embora o efeito familiar trate-se de um aspecto de valor para a organização, suas características também representam riscos; percepção compartilhada por Frank et al. (2016), que destacam que não necessariamente refletirão em sucesso nos negócios. Dou et al. (2019) afirmam que o efeito preciso da relação entre família e negócio ainda não é claro.

Já o senso de propriedade, propriedade, corresponde à posse da empresa e é uma forma de influência, uma vez que concede o direito de uso e poder. Em EFs, a propriedade familiar é fundamental para que o controle organizacional se dê dentro da família e para manutenção do senso de pertencimento dos familiares para com o negócio (familiness). Ainda, contribui para a orientação em longo prazo da empresa, uma vez que a família detém a sua posse (Denicolai et al., 2019; Dou et al., 2019).

O alto percentual de propriedade na firma relaciona-se com maior motivação e envolvimento por parte da família (Zahra, 2003). A posse familiar pode ainda ser interpretada como uma maneira de proteção, pois ao manter o controle internamente, estaria preservando a reputação e a imagem, tanto da empresa quanto da família (Denicolai et al., 2019). Tal instinto de proteção e preservação da família é refletido pela baixa propensão ao risco (Panicker et al., 2019). 
Enquanto Chu (2011) defende que a EF tende a obter mais benefícios quando a propriedade familiar é combinada com forte administração e controle de familiares, autores como Kontinen (2011), Zahra (2018) e Sánchez-Marín et al. (2020) ressaltam que gestores externos à família podem agregar recursos que eventualmente a empresa não possua, especialmente em se tratando do conhecimento com o mercado exterior. Além disso, práticas de profissionalização, como o treinamento formal, estruturação da tomada de decisão, valores meritocráticos, avaliação orientada para resultados, contribuem para a eficácia de EFs, uma vez que minimizam o tratamento preferencial de familiares, e promovem um ambiente mais participativo e profissional (Eddleston et. al., 2018).

Já Santulli et al. (2019) expõem que as firmas atingem melhor desempenho no mercado exterior quando a concentração de propriedade familiar é ou alta ou baixa, ou seja, quando o controle é bastante disperso entre os acionistas familiares ou quando ele se concentra em uma pessoa. O menor desempenho seria aquele em que a propriedade é distribuída igualmente entre os membros da família, tendo em vista eventuais atritos e desalinhamento de objetivos.

Decorrente da análise teórica, o modelo é formado por três grupos de categorias de análise, sendo a primeira composta por familiness e propriedade, a segunda pela percepção de risco e a terceira pela internacionalização.

Consequentemente tem-se a primeira proposição teórica:

Proposição 1. A familiness e propriedade proporcionam o entendimento do risco na propriedadeinternacionalização nas EFs.

Da mesma forma, a elevada percepção de risco influencia a internacionalização, seja pelas estratégias internacionais ou pelos determinantes para IDE. As estratégias são os modos de entrada no exterior (Hollensen, 2017). Já os determinantes de localização são os motivadores para o IDE e se relacionam com as características existentes entre os países de origem e os de destino (Magnani et al., 2018). Considerando as relações apresentadas, a segunda proposição é:

Proposição 2. A percepção de risco proporciona menor grau e escopo de internacionalização.

Na figura 1 apresenta-se o framework teórico resultante.

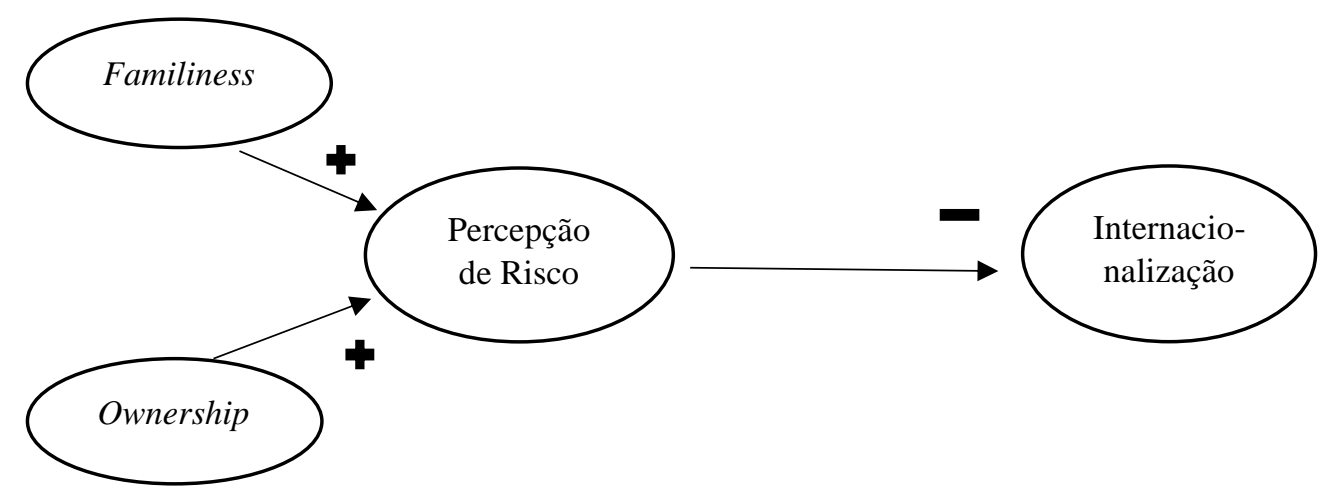

Figura 1. Modelo Teórico

De acordo com o framework (Figura 1), quanto maior for o grau de familiness e propriedade na EF, maior será sua percepção de risco. Por sua vez, a elevada percepção de risco afeta as estratégias da empresa, diminuindo o grau e escopo de internacionalização.

\section{Procedimentos metodológicos}

Esta pesquisa qualitativa busca compreender o significado e natureza atribuída a um problema social ou humano (Creswell, 2010) que interferem nos negócios empresariais. Utilizou-se da estratégia do estudo de caso e foram selecionadas duas EFs, 
denominadas como Empresa A e Empresa B. A seleção das empresas se deu por meio dos seguintes critérios: i) ter pelo menos um membro da família na direção da empresa; ii) ser identificada por seus funcionários com características de EF; iii) dispor de, pelo menos, uma estratégia de internacionalização; iv) ter mais de 10 anos de atuação no mercado nacional.

Como técnica de coleta e análise dos dados, utilizou-se de dados primários e secundários. Os primários foram obtidos por meio de quatro entrevistas semiestruturadas, cuja técnica proporciona detalhamento ao pesquisador (Yin, 2010), sendo duas delas realizadas com gestores familiares e duas com não-familiares. As entrevistas se deram com base em um protocolo de entrevista (Apêndice 1), para que houvesse o mesmo padrão de coleta entre elas. As respostas foram transcritas, detalhadas e analisadas em seu conteúdo. Já os dados secundários foram obtidos por meio de artigos científicos que tratavam de casos das empresas estudadas, materiais disponibilizados pelas empresas como relatórios e folders, bem como as próprias webpages. Após análise dos dados, houve a triangulação entre os dados primários, secundários e a literatura sobre EF. Dados primários e secundários foram analisados conjuntamente para dar maior credibilidade ao estudo (Yin, 2010).

Com base nos critérios de seleção já apresentados, as empresas selecionadas para o estudo encontram-se na segunda geração familiar, tem um membro familiar na direção da empresa, bem como operam internacionalmente. A Empresa $A$ foi fundada em 1938 e é do setor têxtil, enquanto a empresa B foi fundada em 1988 e é do ramo de cordoaria. O tempo de existência, 81 e 31 anos respectivamente, reflete a orientação em longo prazo e a consolidação de mercado de ambas as organizações, permitindo a análise deste estudo.

As entrevistas foram aplicadas durante os meses de agosto e setembro de 2019, ocorreram de forma presencial e tiveram a duração média de 45 minutos cada. Todos os entrevistados aceitaram realizar a entrevista e gravar para posterior transcrição. Os nomes dos entrevistados não foram citados para preservar sua identidade. A relação das pessoas entrevistadas, cargos e respectivas empresas, figuram na Tabela 1. Os entrevistados foram selecionados por serem os responsáveis pela empresa e pelo processo de internacionalização. Os Diretores A e B são membros das famílias fundadoras e os atuais administradores das empresas. O Gerente de exportação $A$ e a Analista de exportação $A$ possuem 10 e 5 anos de empresa respectivamente, e atuam no setor de comércio exterior. Já o Diretor Executivo B, com 13 anos de empresa, está à frente das atividades internacionais da Empresa $\mathrm{B}$ e é o principal responsável pelo IDE e gerenciamento da subsidiária no Paraguai.

\section{Tabela 1}

Relação de entrevistados

\begin{tabular}{l|l|l|l|l}
\hline \multicolumn{1}{c|}{ Empresa } & \multicolumn{1}{|c|}{ Entrevistado } & \multicolumn{1}{c|}{ Tempo } & \multicolumn{1}{c}{ Local } & \multicolumn{1}{c}{ Membro da Família } \\
\hline Empresa A & Diretor A & 1 h15min & Na Empresa A & Sim \\
\hline Empresa A & $\begin{array}{l}\text { Gerente de exportação A } \\
\text { Analista de exportação A }\end{array}$ & $49 \mathrm{~min}$ & Na Empresa A & Não \\
\hline Empresa B & Diretor B & $45 \mathrm{~min}$ & Na Empresa B & Sim \\
\hline Empresa B & Diretor Executivo B & $30 \mathrm{~min}$ & Na Empresa B & Não \\
\hline
\end{tabular}

As entrevistas foram analisadas individualmente pelos dois autores, que depois as analisaram conjuntamente em seu conteúdo. Esse procedimento reduz as discrepâncias de compreensão dos dados (Creswell, 2010). Em caso de informações faltantes os respondentes foram novamente contatados e, prontamente, responderam aos autores. A transcrição final foi enviada aos respondentes para que pudessem verificar as informações contidas e recebermos o consentimento para publicação. Os casos foram comparados ao framework teórico e seus resultados ofereceram contribuições empíricas para elaboração do modelo final. As principais citações adicionais foram incluídas no Apêndice 2 para dar mais transparência à coleta de dados e consistência interna (Yin, 2010). 
Os dados foram analisados em duas etapas. Inicialmente, busca-se compreender o processo individual da internacionalização de cada empresa e identificando as principais categorias de análise estudadas, o processo de internacionalização e a percepção do risco. Em seguida, uma análise conjunta dos dados foi realizada para, por fim, apresentar as proposições resultantes e o modelo empírico.

\section{Apresentação dos casos}

\subsection{Empresa $A$}

A Empresa A encontra-se na segunda geração familiar. $O$ atual presidente do grupo familiar (Diretor A) não possui irmãos ou filhos, o que indica a não continuação da família como gestora do negócio. Porém, percebe-se grande conexão interpessoal entre o diretor e os demais gestores e os filhos dos gestores, pois grande parte deles são amigos de infância e construíram toda sua trajetória profissional na empresa. Possui um presidente externo à família fundadora que já atua na empresa há 30 anos. A empresa faz parte de uma Holding, cujo diretor é o proprietário-familiar, responsável por gerenciar outras duas empresas, centralizando o desenvolvimento de sistemas corporativos, assessoria jurídica e de negócios.

\subsubsection{Processo de Internacionalização}

A exportação iniciou-se na década de 70. Existia uma capacidade ociosa na firma e, por uma situação de mercado, ocorria a venda do produto ao exterior de maneira não estruturada. Gradativamente, houve uma estruturação interna e um planejamento sobre a atividade internacional da empresa. A importação veio posteriormente e rapidamente alcançou grande representatividade, pois além de rentabilidade, proporcionou um mix de produtos mais completo. Em 2019, além da exportação e importação, a empresa instalou um escritório da Holding em Miami, nos Estados Unidos. Os principais mercados de atuação são Paraguai, Estados Unidos, Panamá e Bolívia; justificados pela proximidade com o Brasil, em termos culturais e geográficos. "Por se tratar de um produto de baixo valor agregado, o frete incide significativamente sobre o custo final do produto, facilitando sua comercialização em países mais próximos geograficamente; e, aquele, pois não são necessárias adaptações culturais no produto exportado" (Diretor A).

Em relação ao $I D E$, o escritório de vendas em Miami tem o objetivo de aumentar as vendas ao exterior e alcançar um envolvimento maior com o consumidor final. A firma entende que os Estados Unidos é um grande mercado consumidor, onde, até o momento, só exportou via private label,ou seja, com a marca de terceiros. Com esta nova estratégia, a empresa busca realizar operações diretas, chegando ao ponto de venda no país destino com marca própria e preço mais competitivo. Vale ressaltar que a decisão pelo IDE se deu de forma tardia, visto que ocorreu somente após 40 anos do início das exportações. Como relatado pelo Diretor A, a exportação foi por muito tempo tratada apenas como "mais uma venda", demonstrando pouco engajamento e comprometimento com o exterior.

Em relação à escolha dos Estados Unidos para o IED, "o país tem o maior mercado em termos de PIB, legislação simplificada e tributação favorável, sendo atrativo em termos de tamanho e potencial de crescimento" (Diretor A). É importante ressaltar que a firma optou por Miami, onde há uma proximidade latina, não identificada nas demais regiões, como também presença considerável de brasileiros, que facilita a entrada de outras empresas brasileiras e reduz a percepção de risco.

Para o Gerente A, o futuro prevê um aumento na participação do mercado internacional: "a empresa está concentrada na operação dos Estados Unidos, se trata de um projeto contínuo. A estratégia pode ser adaptada e expandida para outros mercados, caso identificado uma oportunidade internacional".

\section{1. 2. Percepção de risco}

Percebe-se a perspectiva de longo prazo da empresa e a preocupação com o patrimônio construído conforme argumentam os autores Dou et al.(2019); Denicolai et al.(2019) e Lude \& Prügl (2019). A firma investe em pesquisas e feiras internacionais para acompanhar tendências e garantir a manutenção do bom desempenho organizacional. Os entrevistados relatam que o Gerente A faz parte da grande família da empresa, pois carrega consigo quase 30 anos de casa. Desta 
forma, o Diretor A atua mais no conselho do grupo, estabelecendo a orientação e diretrizes para a empresa, comandando todas as empresas do grupo.

Em relação à exposição ao risco, o Diretor A relata: "[...] o nosso pessoal já está acostumado à mudança. Nós costumamos dizer: assumimos qualquer risco, desde que muito bem dimensionado". Ele explica que em determinadas ações há uma resistência inicial; porém quando os colaboradores veem o comprometimento da empresa para com o projeto, há o engajamento de todos do grupo. Por isso, buscase a transparência com as estratégias traçadas e transmitindo a visão do negócio alinhando-se aos achados de Pearson et al., 2008. Percebe-se que as novas estratégias são elaboradas, novos projetos iniciados, porém são estudados pela direção da empresa, independentemente do tempo que levará para a tomada da decisão. Um exemplo é o IDE realizado após 40 anos do início da exportação. 0 comportamento inovador de certa forma, tem se restringido ao mercado interno e, em termos de internacionalização, a percepção de risco ainda influencia consideravelmente as estratégias.

\subsection{Empresa B}

A Empresa B encontra-se na segunda geração familiar e o patriarca já fez a sucessão para seus cinco filhos. Existe um conselho na empresa formado pelos sócios (os cinco irmãos da família) e o Direto Executivo (membro não-familiar), que se reúne para acompanhamento do planejamento estratégico, avaliação de resultados e tomada de decisão. Dentre os sócios, dois trabalham ativamente na empresa, enquanto os outros três irmãos participam apenas como membros do conselho administrativo. As decisões organizacionais são tomadas em consenso, visando uma administração transparente, tanto para os diretores quanto para os sócios.

\section{2. 1. Processo de Internacionalização}

Iniciou seu processo de internacionalização em 2007 por meio da importação, para complementar o mix de produtos com custos inferiores à produção interna. A firma adequou-se com êxito à estratégia de importação e logrou um aumento considerável do volume de vendas. Além disso, de forma esporádica e sem estruturação interna, ocorria a exportação para países vizinhos. Em 2019, além da exportação e importação, a firma construí uma fábrica no Paraguai por meio de greenfiled, ou seja, começando um empreendimento do zero.

A atuação internacional se concentra na América Latina e os três principais países das exportações são Colômbia, Paraguai e Uruguai. O destaque da região é entendido como "oportunidades de mercado, visto que ao participar de feiras, identificou-se nesses mercados um maior interesse pelos produtos $e$ competitividade em preços" (Diretor B). Ainda, questões logísticas, culturais e barreiras alfandegárias mais favoráveis em relação a outros países afetam positivamente para o destaque latino americano. A decisão pelo IDE se deu em um momento de crise econômica e dificuldades cambiais oriundas do grande volume de produtos importados. A instalação da fábrica veio com a intenção de substituir um dos mix de produtos importados por produção própria, diminuindo os custos da cadeia e internalizando o processo. Em 2019 a subsidiária exportou para o Brasil e para outros países da América do Sul.

Vale ressaltar que a decisão pela estratégia de greenfield se deu em um momento de mercado desfavorável e de crise, quando os gestores possivelmente estariam dispostos a aceitar níveis mais elevados de risco, buscando a recuperação do negócio (Lude \& Prügl, 2019). Além disso, percebe-se que o modo de entrada escolhido proporciona à empresa maior controle sobre o processo de internacionalização (Hollensen, 2017). No momento de estabelecer a unidade no exterior, as principais dificuldades deram-se no início do processo (Centeno-Caffarena \& Bocatto, 2006) e seus gestores preocupavam-se sobre como manteriam o controle das atividades a partir do Brasil (Denicolai et al., 2019; Goede et al., 2017). Outro obstáculo foi a obtenção do capital para instalação da subsidiária. Considerando a aversão ao risco, a empresa opta por acumular capital próprio para realizar investimentos (Denicolai et al., 2019). Uma vez instalada, houve um tempo de adaptação com o método de trabalho do Paraguai, devido às diferenças culturais, de administração e contabilidade. O Diretor B explica que "o envolvimento gradativo foi bem-vindo para que a organização pudesse aprender e crescer de maneira sólida evitando demasiada exposição ao risco". Em 2019, a subsidiária contava com um funcionário expatriado do Brasil e cerca de 50 locais. O fato de ter uma pessoa que foi treinada no Brasil é importante para manutenção da cultura e 
metodologia de trabalho. Além disso, o Executivo B viaja a cada duas semanas para o Paraguai, acompanhando a operação. "A gestão no exterior é um ponto desafiador para a empresa e, ser o encarregado por acompanhar a subsidiária e passar a realidade aos sócios da firma, é uma grande responsabilidade" (Executivo $\mathrm{B}$ ).

Quanto à escolha do Paraguai, o país apresenta três grandes vantagens: questões trabalhistas, simplificação e diminuição de impostos e economia de energia. Tais características proporcionam a vantagem competitiva necessária para que a empresa possa disputar com grandes players internacionais, como a China, aproveitando o Sistema Maquila disponibilizado pelo governo paraguaio. O Executivo $B$ relata que, quando houve o projeto para instalação de uma subsidiária no exterior, pensou-se na China. Porém, tanto a distância cultural quanto a geográfica influenciaram de forma negativa esta avaliação. Assim, a empresa optou por um país que apresenta similaridades com o Brasil, desde o idioma, regulamentações, até a própria proximidade territorial; além do programa de benefícios do Sistema Maquila.

O Diretor B destaca: "a internacionalização foi um passo importante para reduzirmos os custos $e$ aumentar a lucratividade. Vale a pena, vamos continuar". O Executivo B destaca que o potencial de crescimento da planta no Paraguai já está acima do da matriz, tanto em tamanho quanto em faturamento: "a internacionalização é um caminho sem volta para a empresa" (Executivo B). A empresa está se expandindo ao exterior de maneira gradativa (Gallo \& Pont, 1996; Graves \& Thomas, 2004) e seus planos para o futuro são aumentar a representação internacional. No entanto, por ora não há pretensão de outras formas de investimento no exterior, visto que não haveria estrutura administrativa e financeira para tal. A empresa aposta no potencial de expansão da subsidiária no Paraguai, assim como no crescimento da matriz no Brasil.

\section{2. 2. Percepção de risco}

Por meio da análise, percebeu-se a perspectiva de longo prazo da empresa (Habbershon \& Williams, 1999; Dou et al., 2019; Lude \& Prügl, 2019) e a preocupação para manutenção da saúde organizacional e do patrimônio familiar (Goede et al., 2017; Panicker et al., 2019). Corroborando com a afirmação de Denicolai et al. (2019) de que a posse familiar é percebida como uma maneira de proteção, o Diretor B comenta: "é uma grande responsabilidade ser um dos gestores à frente da empresa; trata-se de um compromisso assumido perante aos demais familiares, pois sua família depende do sucesso e da rentabilidade do negócio". Ainda, vê-se um senso de pertencimento dos colaboradores para com a empresa, visto que a empresa preza pelo bem-estar e alta fidelidade por parte dos colaboradores (Frank et al., 2016). O patriarca da família iniciou o empreendimento e atualmente acompanha como membro consultivo, visto que já fez a sucessão para seus cinco filhos. Seu exemplo de humildade e força de vontade inspira a segunda geração na busca pelo crescimento e perpetuação de empresa familiar. 0 Diretor B, filho do fundador, salienta: "Estamos trabalhando para ter esta união familiar e perpetuar a geração futura. É um trabalho lento, mas estamos no caminho". Nos primeiros anos de empresa, havia mais membros da família trabalhando na firma; muitos, inclusive, sem formação acadêmica ou experiência na área, o que dificultava a administração da empresa. O Diretor B conta que foi preciso afastar alguns familiares sem qualificação visando a saúde do negócio. Segundo ele, as dificuldades eram maiores quando havia maior número de familiares na empresa. Por outro lado, hoje se está buscando uma maior organização corporativa, com regras e diretrizes para as futuras gerações. Os sócios percebem que é necessário um planejamento para a continuidade da empresa em longo prazo, ou seja, voltar atenção para a preparação de pessoas visando o próximo processo de sucessão. Além de estarem mais integrados com o acompanhamento e estratégias da empresa, por meio do sistema de governança corporativa, implementado há cerca de dois anos.

Em relação à exposição ao risco, o Diretor $B$ explica que a tomada de decisão é compartilhada pelo conselho, deixando todos os envolvidos cientes das estratégias. É perceptível a preocupação com as decisões de alta exposição ao risco, uma vez que afeta não somente a saúde da empresa, como também a vida pessoal de cada um dos familiares. $O$ Executivo B relata: "[...] participando ativamente junto às decisões dos sócios, claro, por ser uma empresa familiar, existem várias restrições, ou cuidados extras, para com o patrimônio da empresa". Faz-se necessário expor de maneira detalhada todo e qualquer trabalho desenvolvido, investimento ou 
estratégia futura. Tomando como exemplo a decisão pela instalação da subsidiária no Paraguai, a aversão ao risco era bastante elevada quando o pré-projeto foi apresentado. O Executivo B conta que foi um susto para os sócios e que houve um longo processo de maturação; com explicações, inúmeras reuniões, apresentações de cases de sucesso, até chegar ao consenso de que valeria a pena o risco do IDE. Para o Diretor B, é uma grande responsabilidade ser um dos gestores à frente da empresa; trata-se de um compromisso assumido perante aos demais familiares, pois sua família depende do sucesso e da rentabilidade do negócio (Denicolai et. al, 2019).

\section{3. Análise conjunta dos casos e proposições}

Tanto a Empresa A quanto a empresa B apresentam aspectos significativos do fator familiness, como orientação em longo prazo (Dou et al., 2019; Denicolai et al., 2019; Lude \& Prügl, 2019) e forte vínculo dos colaboradores com a empresa (Álvares, 2003; Frank et al., 2016). Percebe-se, especialmente na Empresa $A$, a valorização do desenvolvimento dos colaboradores, visto que a empresa tem um programa interno voltado à geração dos futuros executivos. Já na Empresa B, têm-se em destaque $O$ senso de pertencimento e o envolvimento entre os membros da família e a empresa (Cano-Rubio et al., 2016). Os dados indicam alta dependência da família na empresa, pois as decisões organizacionais refletem diretamente na vida pessoal dos membros. Assim, os gestores carregam consigo um senso de responsabilidade elevado em suas ações e a firma preocupa-se em atender às necessidades da família (Denicolai et al., 2019). Já na Empresa $A$, embora não haja membros da família na empresa além do diretor, os amigos do proprietário acabam fazendo este papel e dando continuidade do senso de pertencimento e propriedade.

Na empresa B, viu-se que as decisões são compartilhadas e há o consentimento de todos os sócios antes de se assumir qualquer risco (Chu, 2011; Santulli et al., 2019). O fator de propriedade se dá de forma distinta na Empresa A, visto o forte vínculo interpessoal dos executivos na empresa, que são amigos de infância do Diretor A. Esta característica mantém o aspecto familiness e percepção de risco elevados e favorece um lento processo de internacionalização.
Os dados sugerem uma resistência de ambas as firmas a recursos externos (Graves \& Thomas, 2004), tais como fundos externos de investimento (GomezMejia et al., 2010; Denicolai et al., 2019). Como evidenciado pela Empresa B, este aspecto dificultou o investimento estrangeiro, visto que ele se deu unicamente com recursos próprios. Em relação ao processo de internacionalização, os dados apontam um envolvimento gradual (Gallo \& Pont, 1996; Graves \& Thomas, 2004), tanto em termos de estratégias quanto em países-alvo. Desta forma, as empresas aumentaram seu grau de comprometimento na medida em que adquiriram confiança internacional e aprendizado com suas próprias experiências (Johanson \& Vahlne, 1977).

Embora o primeiro contato com o exterior tenha sido por meio de exportação e importação, modos de menor comprometimento e risco, no momento da decisão por uma estratégia mais avançada, optou-se pelo greenfield. Trata-se de um modo de entrada de maior autonomia e envolvimento com o país destino, pois internaliza as etapas e detém o controle do processo (Hollensen, 2017). Percebe-se também que as empresas não utilizam de redes de contato no exterior em suas estratégias de internacionalização (Graves \& Thomas, 2004), possivelmente com a intenção de manter a gestão centralizada e de se expor menos a terceiros. Outro aspecto de internalização é que ambas possuem no exterior um funcionário de confiança expatriado do Brasil, responsável por realizar a comunicação com a matriz. É necessário destacar a diferença de tempo para o IDE. Enquanto na Empresa B ocorreu após cerca de 10 anos do início da internacionalização, na Empresa A tardou mais de 40 anos para que se tomasse uma estratégia de maior risco e comprometimento com o exterior.

Em relação aos determinantes de localização, há na exportação uma concentração de mercados na América Latina, em grande parte devido à proximidade cultural e geográfica (Hutzschenreuter et al., 2015; Hernández et al., 2017). As empresas também consideram a questão da cultura na escolha do mercado estrangeiro. A similaridade cultural facilita a relação comercial (Ferreira \& Falcão, 2019), pois aproximam características de consumo e de mercado para maior aceitação dos produtos e/ou serviços no país destino. Na Empresa B, quando se decidiu pelo investimento no exterior, foi cogitado o mercado chinês, porém o aspecto das distâncias 
existentes entre os países foi determinante para que se optasse pelo Paraguai.

Percebe-se que as decisões das empresas são influenciadas pelos próprios objetivos estratégicos. A Empresa A, por exemplo, almejava estar presente no exterior com maior comprometimento para aumentar sua participação no cenário internacional. Assim, optou pelos Estados Unidos por possuir indicadores econômicos elevados e com grande potencial de crescimento para a firma, especialmente Miami pela proximidade. Já a Empresa B, buscava redução de custos e se estabeleceu no Paraguai, por proporcionar principalmente o Sistema Maquila. Percebe-se que as decisões estratégicas se alinham com as oportunidades de mercado identificadas pelas empresas e com os objetivos traçados por elas.

O Quadro 1 apresenta as principais categorias analisadas e os principais resultados encontrados nos casos analisados

Tendo em vista o exposto, os dados sugerem convergência com o framework teórico apresentado. No entanto, embora o framework se confirme, o estudo sugere a presença de dois aspectos que afetam esta relação: objetivos estratégicos e operacionalização por não familiar; além da conexão direta e mútua entre familiness e propriedade. $\mathrm{Na}$ figura 2, pode-se observar as considerações do modelo empírico com base nos casos.

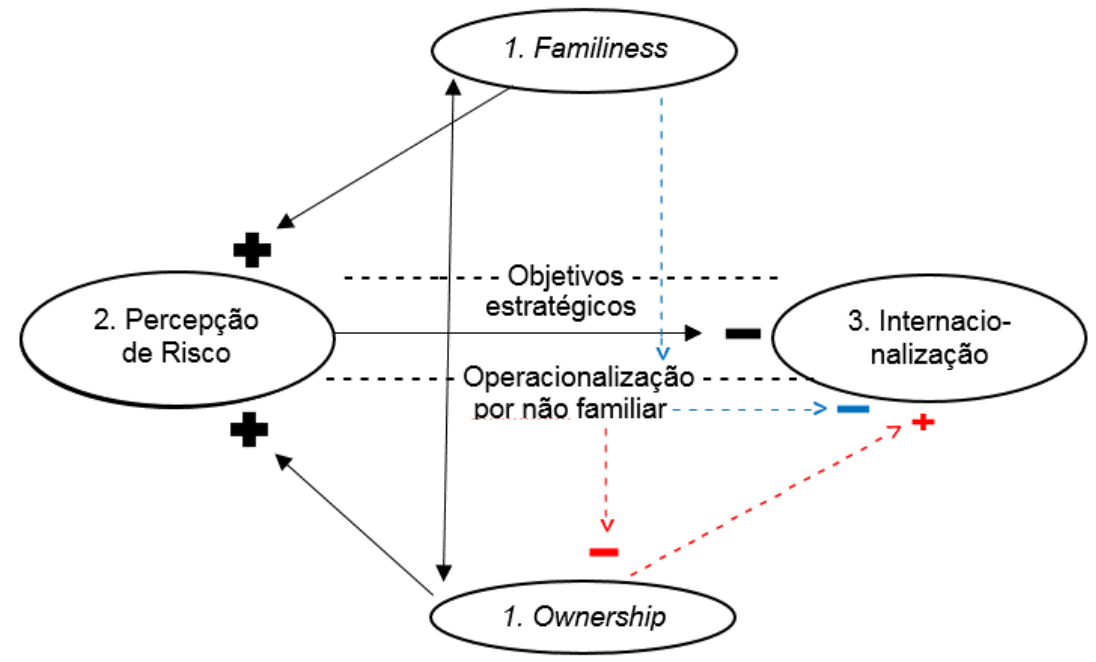

Figura 2. Modelo Empírico

Como exposto no framework teórico (Figura 1), quanto mais familiness e propriedade, maior é a percepção de risco e, como consequência, menor sua internacionalização. Todavia, acrescentam-se os objetivos estratégicos e operacionalização por não familiar. O primeiro aspecto diz respeito às próprias metas das empresas e oportunidades de mercado. A identificação de um objetivo estratégico sólido e claro influencia o processo de internacionalização, podendo se sobressair ante a percepção de risco.

Já em relação ao segundo aspecto, as empresas possuem gestores à frente da estratégia internacional que não são membros da família. Esta característica de certa forma reduz o grau de propriedade na organização e contribui para intensificar a internacionalização; como ilustrado nas linhas em vermelho do modelo empírico. O comportamento destes executivos é primordial para atenuar a percepção de risco oriunda da proteção familiar e conduzir a firma para estratégias de maior envolvimento internacional. Todavia, a linha azul mostra que o aspecto familiness ainda é intenso a ponto de ser transferido à operacionalização por nãofamiliar. Estes profissionais sentem que suas decisões afetam diretamente os membros da família; logo, administram com elevado senso de responsabilidade, reportando toda e qualquer ação estratégica à família; aspecto que pode ser uma barreira para a internacionalização.

Sendo assim, as proposições finais deste estudo são:

Proposição Final 1. A presença de profissionais externos à família reduz o grau de propriedade $e$ contribui para intensificar a internacionalização da empresa familiar. 
Proposição Final 2. O elevado grau de familiness, diminui o efeito da influência do profissional externo e a internacionalização.

Proposição Final 3. A elevada conexão entre objetivos estratégicos e a internacionalização, diminui o efeito negativo da percepção de risco.

\section{Conclusão}

As proposições teóricas conduziram o direcionamento desta pesquisa, demonstrando que familiness e propriedade proporcionam o entendimento do risco e reduz o grau e o escopo de internacionalização nas EFS. Assim, com base nos casos apresentados, elaborou-se um modelo empírico e observou-se convergência com o modelo teórico. Identificaram-se duas categorias adicionais que influenciam a internacionalização das empresas familiares estudadas: objetivos estratégicos e operacionalização por não familiar.

Infere-se que o risco não impede a internacionalização das firmas, porém contribui para que aconteça em áreas geográficas próximas, número limitado de países e por meio de estratégias de internalização de menor risco e maior controle.

Mesmo com a presença de gestores externos, o fator familiness é intenso a ponto de seu efeito ser transferido para a operacionalização por nãofamiliar. Desta forma, os profissionais externos absorvem a pressão familiar e administram com elevado senso de responsabilidade. Embora haja menor propriedade familiar pela presença do profissional externo, tal influência se reflete na elevada percepção de risco, podendo ser uma barreira à internacionalização. Portanto, para que o papel de um profissional externo à família à frente do comércio exterior seja positivo, é preciso garantir a não transferência de fortes características de familiness.

A partir da análise dessa pesquisa verificou-se ainda a importância de ter objetivos claros e sólidos na estratégia internacional (Magnani, Zucchella \& Floriani, 2018). Desta forma, quando identificado oportunidades de mercado que vão ao encontro ao objetivo estratégico da empresa familiar, a percepção de risco tende a influenciar menos o processo de internacionalização.
Como contribuição empírica para as EFs, esses resultados demonstram não só como a percepção do risco pode influenciar as oportunidades estratégicas para aumentar a rentabilidade organizacional, como também a relevância do gestor não-familiar em uma EF. Ainda, EF com objetivos estratégicos claros, pode minimizar os efeitos de familiness e ter uma internacionalização mais efetiva. Para outras empresas familiares, este estudo apresenta a relevância da participação de gestores não-familiares na execução das estratégias de internacionalização. Gestores não-familiares, com o passar do tempo, incorporam o familiness, incorporando o cuidado com os bens familiares e ao mesmo tempo reduzindo a aversão ao risco.

Apesar do número de casos estudados ser considerado baixo, o objetivo desta pesquisa não foi a diversidade de casos e sim a consistência das entrevistas, o alinhamento com os dados secundários e a diversificação de entrevistas, de modo a permitir um conhecimento adequado sobre os casos. Portanto, a limitação está na diversidade das categorias analisadas. Sabe-se que outras categorias podem influenciar o processo de internacionalização. Propõe-se, como sugestão para futuras pesquisas, expandir a presente análise para empresas de diferentes segmentos e países de origem, a fim de verificar diferenças e similaridades com o modelo empírico apresentado. Considera-se relevante, ainda, realizar este estudo simultaneamente com EFs e nãofamiliares, visto que proporcionaria riqueza na análise e comparação entre as distintas categorias de análise.

\section{Referências}

Álvares, E. (2003). Governando a empresa familiar. Qualitymark Editora Ltda.

Arregle, JL., Hitt, M.A. \& Mari, I. A missing link in family firms' internationalization research: Family structures. J Int Bus Stud 50, 809-825 (2019). https://doi.org/10.1057/s41267-019-00213-z

Basco, R. (2018). Family business in emerging markets. In The Oxford Handbook of Management in Emerging Markets. 
Cano-Rubio, M., Fuentes-Lombardo, G., Hernández-Ortiz, M. J., \& Vallejo-Martos, M. C. (2016). Composition of familiness: Perspectives of social capital and open systems. European Journal of Family Business, 6(2), https://doi.org/10.1016/j.ejfb.2016.12.002

Centeno-Caffarena, L., \& Bocatto, E. (2006). The internationalization of Family Business: state-of-theart and comprehensive research framework. In 3rd EDP WORKSHOP.

Chua, J. H., Chrisman, J. J., \& Sharma, P. (1999). Defining the family business by behavior. Entrepreneurship theory and practice, 23(4), 19-39. https://doi.org/10.1177/104225879902300402

Chu, W. (2011). Family ownership and firm performance: Influence of family management, family control, and firm size. Asia Pacific Journal of Management, 28(4), 833-851. DOI 10.1007/s10490009-9180-1

Creswell, J. W. (2010). Projeto de pesquisa métodos qualitativo, quantitativo e misto. In Projeto de pesquisa métodos qualitativo, quantitativo e misto. Porto Alegre: Artmed.

Daspit, J. J., Long, R. G., \& Pearson, A. W. (2019). How familiness affects innovation outcomes via absorptive capacity: A dynamic capability perspective of the family firm. Journal of Family Business Strategy, 10(2), 133-143. https://doi.org/10.1016/j.jfbs.2018.11.003

De Massis, A., Frattini, F., Majocchi, A., \& Piscitello, L. (2018). Family firms in the global economy: Toward a deeper understanding of internationalization determinants, processes, and outcomes. Global Strategy Journal, 8(1), 3-21. https://doi.org/10.1002/gsj.1199

Denicolai, S., Hagen, B., Zucchella, A., \& Dudinskaya, E. C. (2019). When less family is more: Trademark acquisition, family ownership, and internationalization. International Business Review, 28(2), 238-251. https://doi.org/10.1016/j.ibusrev.2018.09.002
Dou, J., Jacoby, G., Li, J., Su, Y., \& Wu, Z. (2019). Family involvement and family firm internationalization: The moderating effects of board experience and geographical distance. Journal of International Financial Markets, Institutions and Money, 59, 250-261. https://doi.org/10.1016/j.intfin.2018.12.004

Eddleston, K., Sarathy, R., Banalieva. E. (2018) When a high-quality niche strategy is not enough to spur family-firm internationalization: The role of external and internal contexts. Journal of International Business Studies.

Ferreira, M. P., \& Falcão, M. B. (2019). O impacto das Distâncias Institucionais CAGE e das Motivações para a Internacionalização sobre o Investimento Direto Estrangeiro Brasileiro. Brazilian Business Review, 16(2), 154-173. DOI: http://dx.doi.org/10.15728/bbr.2019.16.2.4

Frank, H., Kessler, A., Rusch, T., Suess-Reyes, J., \& Weismeier-Sammer, D. (2017). Capturing the familiness of family businesses: Development of the family influence familiness scale (FIFS). Entrepreneurship Theory and Practice, 41(5), 709-742. https://doi.org/10.1111/etap.12229

Gallo, M. A., \& Pont, C. G. (1996). Important factors in family business internationalization. Family Business Review, 9(1), 45-59. https://doi.org/10.1111/j.1741-6248.1996.00045.x

Goede, W., Floriani, D. E., \& Furtado Filho, A. (2018). Family influence on internationalization: an analysis of risk acceptance. Revista de Negócios, 22(1), 8-19.

Gomez-Mejia, L. R., Makri, M., \& Kintana, M. L. (2010). Diversification decisions in family-controlled firms. Journal of management studies, 47(2), 223252. https://doi.org/10.1111/j.14676486.2009.00889.x

Graves, C., \& Thomas, J. (2004). Internationalisation of the family business: a longitudinal perspective. International Journal of Globalisation and Small Business, 1(1), 7-27. https://doi.org/10.1504/IJGSB.2004.005615 
Habbershon, T. G., \& Williams, M. L. (1999). A resource-based framework for assessing the strategic advantages of family firms. Family business review, 12(1), 1-25. https://doi.org/10.1111/j.17416248.1999.00001.x

Hernández, V., Nieto, M. J., \& Boellis, A. (2018). The asymmetric effect of institutional distance on international location: Family versus nonfamily firms. Global Strategy Journal, 8(1), 22-45. https://doi.org/10.1002/gsj.1203

Hollensen, S. (2017). Global Marketing (7th ed). London: Pearson.

Hutzschenreuter, T., Kleindienst, I., \& Lange, S. (2015). The concept of distance in international business research: A review and research agenda. International Journal of Management Reviews, 1-20. DOI: 10.1111/ijmr.12065

Johanson, J., \& Vahlne, J. E. (1977). The internationalization process of the firm-a model of knowledge development and increasing foreign market commitments. Journal of international business studies, 8(1), 23-32. https://doi.org/10.1057/palgrave.jibs.8490676

Kontinen, T. (2011). Internationalization pathways of family SMEs. Jyväskylä studies in business and economics, (100).

Kretinin, A., Samuel, J., \& Kashyap, R. (2019). Do Family Firms Prefer Global Intensity to Global Reach? An Analysis of the Role of Geographical and Cultural Distances Upon Internationalization of Family Firms. Journal of Business and Economic Studies, 23(1), 55-72.

Lude, M., \& Prügl, R. (2019). Risky decisions and the family firm bias: An experimental study based on prospect theory. Entrepreneurship Theory and Practice, 43(2), https://doi.org/10.1177/1042258718796078

Magnani, G., Zucchella, A., \& Floriani, D. E. (2018). The logic behind foreign market selection: Objective distance dimensions vs. strategic objectives and psychic distance. International Business Review, 27(1), 1-20. https://doi.org/10.1016/j.ibusrev.2017.10.009

Manogna, R., Kumar, A., Sinha. A. (2020) Does institutional ownership affect firms' international investments? Empirical evidence from India. Department of Economics, Birla Institute of Technology and Science, Pilani- K. K. Birla Goa Campus, Sancoale, India

Monticelli, J.M., Bernardon, R. and Trez, G. (2018), "Family as an institution: the influence of institutional forces in transgenerational family businesses", International Journal of Entrepreneurial Behavior and Research, Vol. 47, pp. 777-780

Odom, D. L., Chang, E. P., Chrisman, J. J., Sharma, P., \& Steier, L. (2019). The most influential family business articles from 2006 to 2013 using five theoretical perspectives. In The Palgrave handbook of heterogeneity among family firms (pp. 41-67). Palgrave Macmillan, Cham.

Panicker, V., Mitra, S., Upadhyayula, R. (2019). Institutional investors and international investments in emerging economy firms: A behavioral risk perspective. Journal of World Business.

Pearson, A. W., Carr, J. C., \& Shaw, J. C. (2008). Toward a theory of familiness: A social capital perspective. Entrepreneurship theory and practice, 32(6), 949-969. https://doi.org/10.1111/j.1540-6520.2008.00265.x

PricewaterhouseCoopers Brasil. (2017). A conexão que faltava: a importância do planejamento estratégico par ao sucesso da empresa familiar. Recuperado de https://www.pwc.com.br/pt/setoresde-atividade/empresas-

familiares/2017/tI_pgef_17.pdf

Sánchez-Marín, G., Pemartín, M., \& MonrealPérez, J. (2020). The influence of family involvement and generational stage on learning-by-exporting among family firms. Review of Managerial Science, 14(1), 311-334. https://doi.org/10.1007/s11846-019-00350-7

Santulli, R., Torchia, M., Calabrò, A., \& Gallucci, C. (2019). Family ownership concentration and firm internationalization: integrating principal-principal and socioemotional wealth perspectives. Journal of International Entrepreneurship, 17(2), 220-248. https://doi.org/10.1007/s10843-019-00245-4 
Soeth, L. F., \& Ern, J. P. F. (2017). Internacionalização ou internalização?. Revista Alcance (Online), 24(3), 433-444. DOI: alcance.v24n3.p433-444

Süss, J., \& Weismeier-Sammer, D. (2013). Familiness: Der Einfluss der Familie auf das Unternehmen. Austrian Management Review, 3.

Yin, R. (2010). Estudo de Caso: Planejamento e Métodos (4th ed.). Porto Alegre: Bookman.
Zahra, S. A. (2003). International expansion of US manufacturing family businesses: The effect of ownership and involvement. Journal of business venturing, 18(4), 495-512. https://doi.org/10.1016/S0883-9026(03)00057-0

Zahra, S. A. (2018). Entrepreneurial risk taking in family firms: The wellspring of the regenerative capability. Family Business Review, 31(2), 216-226. https://doi.org/10.1177/0894486518776871

Isabella Spengler - Hof University of Applied Sciences, (Alemanha). E-mail: spenglerisabella@gmail.com Orcid id: https://orcid.org/0000-0003-3086-7345

Dinorá Eliete Floriani - Universidade do Vale do Itajaí - UNIVALI, Santa Catarina, (Brasil). E-mail: dinora@univali.br Orcid id: https://orcid.org/0000-0001-7898-284X 


\title{
RISK PERCEPTION IN THE INTERNATIONALIZATION OF FAMILY BUSINESSES
}

\author{
Isabella Spengler \& Dinorá Eliete Floriani \\ Hof University of Applied Sciences, (Alemanha). \\ Universidade do Vale do Itajaí - UNIVALI, Santa Catarina, (Brasil)
}

\begin{tabular}{l} 
ARTICLE DETAILS \\
\hline Article history: \\
Received: 15 september 2020 \\
Accepted: 07 september 2021 \\
Available online november: 12 th 2021 \\
Double Blind Review System \\
Scientific Editor \\
Ilan Avrichir \\
\hline Keywords \\
Internationalization \\
Family business \\
Risk Perception
\end{tabular}

ABSTRACT
Objective: This study aims to understand how risk perception affects the
internationalization process in family businesses.
Method: This article presents a qualitative approach and uses the case study
strategy. Semi-structured interviews were carried out with family and non-
family managers of two family businesses.
Main results: Convergence between theoretical and empirical models is
identified with the complementarity of two new categories of analysis in the
empirical model, strategic objectives and operationalization by non-family
members, which influence the relationship and can result in a greater or lesser
degree of internationalization.
Relevance/Originality: The perception of risk is an important aspect in the
internationalization of family businesses from emerging countries and it is
necessary to intensify studies that analyze its effects on international strategies.
This study presents the influence of two categories that proved to be relevant
to the internationalization process of FBs, in addition to the effects already seen
in the literature, the strategic objectives and operationalization by non-family
members.
Contributions: This study contributes to the insertion of strategic objectives and
the presence of a manager external to the family in the face of
internationalization, which mitigate the perception of risk and contribute to
strategies of greater international involvement. When found the familiness
between managers of the cases studied, it was realized a capacity of same
transfer this value to non-family members. On the other hand, family
businesses can, through the connections established, reevaluate their
strategies in order to obtain better results in internationalization.




\title{
PERCEPCIÓN DE RIESGO EN LA INTERNACIONALIZACIÓN DE EMPRESAS FAMILIARES
}

\author{
Isabella Spengler \& Dinorá Eliete Floriani \\ Hof University of Applied Sciences, (Alemanha) \\ Universidade do Vale do Itajaí - UNIVALI, Santa Catarina, (Brasil)
}

\begin{tabular}{l}
\hline DETALLES DEL ARTÍCULO \\
\hline Historia del Artículo: \\
Recibido: 15 de septiembre de 2020 \\
Aceptado: 07 de septiembre de 2021 \\
Disponible en línea: 12 de noviembre 2021 \\
Double Blind Review System \\
Editor Científico \\
Ilan Avrichir \\
\hline
\end{tabular}

\section{Palabras-clave:}

Internacionalización

Empresa familiar

Percepción del riesgo

\section{RESUMEN}

Objetivo: Este estudio tiene como objetivo comprender cómo la percepción de riesgo afecta el proceso de internacionalización en las empresas familiares (EF).

Método: Este artículo presenta un enfoque cualitativo y utiliza la estrategia de estudio de caso. Se realizaron entrevistas semiestructuradas con directivos familiares y no familiares de dos empresas familiares.

Resultados principales: Se identifica la convergencia entre modelos teóricos y empíricos con la complementariedad de dos nuevas categorías de análisis en el modelo empírico, objetivos estratégicos y operacionalización por no familiares, que influyen en la relación y pueden resultar en un mayor o menor grado de internacionalización.

Relevancia / originalidad: La percepción del riesgo es un aspecto importante en la internacionalización de las empresas familiares de países emergentes y es necesario intensificar los estudios que analicen sus efectos en las estrategias internacionales. Este estudio presenta la influencia de dos categorías que resultaron relevantes para el proceso de internacionalización de las EF, además de los efectos ya vistos en la literatura, los objetivos estratégicos y la operacionalización por no familiares.

Aportes teórico-metodológicos: Este estudio contribuye a la inserción de objetivos estratégicos y la presencia de un directivo fuera de la familia de cara a la internacionalización, lo que mitiga la percepción de riesgo y contribuye a estrategias de mayor implicación internacional. Cuando se verificó la familiaridad entre los gestores de los casos estudiados, se notó la capacidad de los mismos para traspasar este valor a los no familiares. Estos aspectos pueden convertirse en una barrera para la internacionalización. Por otro lado, las empresas familiares pueden, a través de vínculos establecidos, reevaluar sus estrategias para obtener mejores resultados en la internacionalización

\section{Como citar este artigo:}

Spengler, I., \& Floriani, D. E. (2022). Percepção de Risco na Internacionalização de Empresas Familiares. Internext, 17(1), 22-45. https://doi.org/10.18568/internext.v17i1.630 
Apêndice 1: Protocolo de Entrevistas

\begin{tabular}{|c|c|c|}
\hline Perguntas & Base Teórica & Autores \\
\hline $\begin{array}{l}\text { Qual é hoje a geração responsável } \\
\text { pela gestäo da empresa? }\end{array}$ & $\begin{array}{l}\text { Período de transição pode acarretar em uma ruptura nos negócios / Apenas } \\
12 \% \text { dos empreendimentos familiares chegam a terceira geraçăo/ S Sucessäo em } \\
\text { EF é positivo para o desempenho; une experiência e expertise de antigas } \\
\text { geraçôes, com conhecimento e perspectivas renovadas de novos membros / } \\
\text { Gerações preparadas e capacitadas para assumir a empresa da familia. }\end{array}$ & $\begin{array}{l}\text { (Alayo, Maseda, Iturralde, \& } \\
\text { Arzubiaga, 2019; Arzubiaga; } \\
\text { Maseda \& Iturralde, 2019; Pwc; } \\
\text { 2017). }\end{array}$ \\
\hline $\begin{array}{l}\text { A família se preocupa com a } \\
\text { continuidade do negócio? Há a } \\
\text { intençăo de que as seguintes } \\
\text { geraçóes sigam com a empresa da } \\
\text { familia? }\end{array}$ & $\begin{array}{l}\text { Alto grau de longevidade / Orientaçăo em longo prazo é uma vantagem para as } \\
\text { EF. }\end{array}$ & $\begin{array}{l}\text { (Denicolai, Hagen, Zucchella, \& } \\
\text { Dudinskaya, 2019; Gallo \& Pont, } \\
\text { 1996; Lude \& Prügl, 2019). }\end{array}$ \\
\hline $\begin{array}{l}\text { Manter a empresa em posse da } \\
\text { familia é um objetivo importante } \\
\text { para a empresa? }\end{array}$ & $\begin{array}{l}\text { O alto percentual de propriedade na firma relaciona-se com maior motivação e } \\
\text { envolvimento por parte da familia / Posse familiar = uma maneira de proteçäo; } \\
\text { preservando a reputaçäo e a imagem, controle interno / Firmas com melhor } \\
\text { desempenho no mercado exterior quando a concentração de propriedade } \\
\text { familiar é bastante disperso ou concentrado em uma pessoa / Less Family is } \\
\text { more = desempenho internacional melhora quando a propriedade da familia é } \\
\text { menor. }\end{array}$ & $\begin{array}{l}\text { (Denicolai et. al., 2019; Santulli, } \\
\text { Torchia, Calabro, \& Galucci, 2019; } \\
\text { Zahra, 2003). }\end{array}$ \\
\hline $\begin{array}{l}\text { O que a empresa significa para } \\
\text { você? (Senso de pertencimento, } \\
\text { significado pessoal, laço } \\
\text { emocional, nome da familia ligado } \\
\text { ao da empresa e vice versa) }\end{array}$ & $\begin{array}{l}\text { Fomiliness = envolvimento familiar, essência e identidade de EF. / Representa } \\
\text { um senso de pertencimento do negócio para com a familia, e vice-versa; } \\
\text { recursos diferenciados. }\end{array}$ & $\begin{array}{l}\text { [Cano-Rubio, Fuentes-Lombardo, } \\
\text { Hernandez-Ortiz, \& Vallejo- } \\
\text { Martos, 2016; Habbershon \& } \\
\text { Williams, 1999; Süss \& Weismeier- } \\
\text { Sammer, 2013). }\end{array}$ \\
\hline $\begin{array}{l}\text { Como você percebe a conexăo da } \\
\text { empresa com os colaboradores e } \\
\text { com os clientes de forma geral? Há } \\
\text { uma imagem positiva? }\end{array}$ & $\begin{array}{l}\text { Alto grau de confiabilidade nos negócios - percebido por clientes e } \\
\text { colaboradores / valores fortes, preocupação com o legado construído; lealdade } \\
\text { entre funcionários / sentimento de pertencimento e expectativa de fidelidade } \\
\text { dos colaborados / Imagem ligada a familia - preocupaçäo em mantê-la positiva } \\
\text { / Busca por r relacóes solidas com clientes e fornecedores. }\end{array}$ & $\begin{array}{l}\text { (Álvares, 2003; Lude \& Prügl, } \\
\text { 2019; Pwc, 2018). }\end{array}$ \\
\hline
\end{tabular}




\begin{tabular}{|c|c|c|}
\hline $\begin{array}{l}\text { Na sua percepção, a família está } \\
\text { aberta para novas estratégias da } \\
\text { empresa, ou há resistência? }\end{array}$ & $\begin{array}{l}\text { EF tende a se diversificar menos do que a não familiar / Resistencia a } \\
\text { mudança / Cenário positivo = EF evitam decisões estratégicas arriscadas, } \\
\text { visando manutençäo do seu desempenho no longo prazo, proteção } \\
\text { patrimônio e riqueza acumulada / Cenário desfavorável e de crise = } \\
\text { gestores dispostos a aceitar niveis mais altos de risco, buscando } \\
\text { recuperação do negócio. }\end{array}$ & $\begin{array}{l}\text { (Gomez-Mejia; Makri \& Kintana, } \\
\text { 2010; Lude \& Prügl, 2019; Zahra, } \\
\text { 2018). }\end{array}$ \\
\hline $\begin{array}{l}\text { Como surgiu o projeto da expansão a } \\
\text { mercados internacionais? }\end{array}$ & $\begin{array}{l}\text { Processo de internacionalização iniciado mais tarde do que as não } \\
\text { familiares. }\end{array}$ & $\begin{array}{l}\text { (Gallo \& Pont, 1996; Graves \& } \\
\text { Thomas, 2004). }\end{array}$ \\
\hline $\begin{array}{l}\text { Qual foi o primeiro contato da } \\
\text { empresa com o exterior? como se deu } \\
\text { esta escolha? }\end{array}$ & $\begin{array}{l}\text { EF optam por países de menor distância psíquica. Aumentando seu grau } \\
\text { de comprometimento e confiança na medida que adquirem experiência. }\end{array}$ & $\begin{array}{l}\text { (Gallo \& Pont, 1996; Graves \& } \\
\text { Thomas, 2004). }\end{array}$ \\
\hline $\begin{array}{l}\text { Houve resistência da família para o } \\
\text { inicio da internacionalizaçäo? }\end{array}$ & $\begin{array}{l}\text { EF menos propensas a se internacionalizarem em comparação às não } \\
\text { familiares. }\end{array}$ & (Graves \& Thomas, 2004). \\
\hline $\begin{array}{l}\text { Baseado na sua experiência, você pode } \\
\text { relatar quais foram as principais } \\
\text { dificuldades enfrentadas no início do } \\
\text { processo? }\end{array}$ & $\begin{array}{l}\text { Para EF a principal díficuldade é } \circ \text { início do processo de } \\
\text { internacionalização. }\end{array}$ & $\begin{array}{l}\text { (Centeno-Caffarena \& Bocatto, } \\
\text { 2006; Graves \& Thomas, 2004). }\end{array}$ \\
\hline $\begin{array}{l}\text { Qual foi o primeiro país para onde a } \\
\text { empresa se expandiu e por quê? }\end{array}$ & Determinantes de localização. & $\begin{array}{l}\text { (Magnani; Zucchella \& Floriani, } \\
\text { 2018). }\end{array}$ \\
\hline $\begin{array}{l}\text { E em relação a distáncia geográfica? } \\
\text { Você percebe a preferência por parte } \\
\text { da empresa para países mais próximos } \\
\text { geograficamente? }\end{array}$ & $\begin{array}{l}\text { Incertezas no processo de internacionalização aumentam } \\
\text { proporcionalmente à distância / Distanciamento geográfico é uma forte } \\
\text { barreira frente ao comércio exterior, visto o alto custo de transporte e } \\
\text { lead time embutidos. }\end{array}$ & $\begin{array}{l}\text { (Hernández, Nieto, \& Boellis, 2017; } \\
\text { Hutzschenreuter, Kleindienst, \& } \\
\text { Langue, 2015; Kovacs, De Moraes } \\
\text { \& De Oliveira, 2011). }\end{array}$ \\
\hline $\begin{array}{l}\text { Hoje em dia, quais são as operações } \\
\text { internacionais que a empresa possui? } \\
\text { como se deu esta escolha de } \\
\text { mercados? }\end{array}$ & $\begin{array}{l}\text { Não somente as distáncias afetam a escolha dos paises no processo de } \\
\text { internacionalização. Outros aspectos como o próprio plano estratégico da } \\
\text { firma e natureza do negócio afetam. }\end{array}$ & 018). \\
\hline
\end{tabular}




\begin{tabular}{|c|c|c|}
\hline $\begin{array}{l}\text { Na medida em que a empresa adquiriu } \\
\text { experiência, aumentou o número de } \\
\text { países de atuaçäo? por quê? }\end{array}$ & $\begin{array}{l}\text { Inicialmente mercados de maior similaridade para, posteriormente, } \\
\text { projetar-se em países de distanciamento superior / Comprometimento } \\
\text { crescente e gradativo com a internacionalização / Não necessariamente a } \\
\text { internacionalização se dá de maneira gradual. }\end{array}$ & $\begin{array}{l}\text { (Johanson \& Vahlne, 1977; } \\
\text { Magnani et. al., 2018; Welch \& } \\
\text { Luostarinen, 1988). }\end{array}$ \\
\hline $\begin{array}{l}\text { A empresa tem parcerias no exterior? } \\
\text { (Outras empresas, associaçōes } \\
\text { industriais, agểncias governamentais, } \\
\text { alianças internacionais) }\end{array}$ & $\begin{array}{l}\text { Menos propensas a se envolverem em uma rede de contatos no exterior - } \\
\text { > relutantes na busca por recursos externos, ao se voltarem mais à } \\
\text { internalização da empresa / Parcerias locais podem contribuir para a } \\
\text { diminuição das distâncias entre o país de origem e o de destino. }\end{array}$ & (Graves \& Thomas, 2004). \\
\hline $\begin{array}{l}\text { Houve influência deste tipo de relação } \\
\text { no momento de escolher os mercados } \\
\text { no exterior? }\end{array}$ & $\begin{array}{l}\text { Firmas são mais propensas a entrar em um mercado com maior distância } \\
\text { institucional positiva (grau institucional mais elevado em relação ao de } \\
\text { origem) = ambiente mais seguro para os negócios. / Menos propensas a } \\
\text { investir naqueles com maiores distâncias institucionais negativas (aumenta } \\
\text { o grau de incerteza da operação). }\end{array}$ & $\begin{array}{l}\text { (Hernández, Nieto, \&. Boellis, } \\
\text { 2017). }\end{array}$ \\
\hline $\begin{array}{l}\text { Como é hoje o cenário político e } \\
\text { econômico dos paises de atuação da } \\
\text { empresa? (Se há incentivos, apoio, } \\
\text { realidade institucional) }\end{array}$ & $\begin{array}{l}\text { O desempenho de EFs se destaca em um ambiente de menor grau de } \\
\text { institucionalidade, pois este se torna mais propício para o } \\
\text { desenvolvimento de redes informais. }\end{array}$ & $\begin{array}{l}\text { (Hernández, Nieto, \& Boellis, } \\
\text { 2017). }\end{array}$ \\
\hline $\begin{array}{l}\text { Na sua opiniäo, o fato de ser uma } \\
\text { empresa familiar, faz com que ela seja } \\
\text { mais conservadora em suas } \\
\text { estratégias? (Como o risco se } \\
\text { manifesta nas decisões estratégicas da } \\
\text { empresa?) }\end{array}$ & $\begin{array}{l}\text { Preservar a riqueza socioemocional da empresa influencia a tomada de } \\
\text { decisóes das EFs / Adversa ao risco. }\end{array}$ & $\begin{array}{l}\text { (Centeno-Caffarena \& Bocatto, } \\
\text { 2006; Gomez-Mejia et. al., 2010; } \\
\text { Graves \& Thomas, 2004). }\end{array}$ \\
\hline $\begin{array}{l}\text { Há a preocupação por parte da família } \\
\text { de garantir a sobrevivência da } \\
\text { empresa para as próximas geraçōes? } \\
\text { lsso a faz agir de forma menos } \\
\text { arriscada? }\end{array}$ & $\begin{array}{l}\text { Postura mais cautelosa, pois, buscam diminuição de riscos e proteção de } \\
\text { um legado construido e não exposiçã̃o ao risco / A aversão ao risco à SEW } \\
\text { tem prioridade sobre a aversão às perdas financeiras. }\end{array}$ & 2018). \\
\hline
\end{tabular}




\begin{tabular}{|c|c|c|}
\hline $\begin{array}{l}\text { Baseado na sua experiência, a família } \\
\text { vê recursos externos (como } \\
\text { financiamento, cargos de gerência } \\
\text { ocupados por não membros da família) } \\
\text { como uma ameaça? }\end{array}$ & $\begin{array}{l}\text { Resistência para recursos externos é um dificultador. EF relutante para } \\
\text { financiamento e contratações externas pela ameaça de perda do controle. }\end{array}$ & $\begin{array}{l}\text { [Denicolai et. al, 2019; Gomez- } \\
\text { Mejia et. al., 2010; Graves \&. } \\
\text { Thomas, 2004). }\end{array}$ \\
\hline $\begin{array}{l}\text { Ou há uma postura empreendedora da } \\
\text { empresa que a faz agir de forma } \\
\text { inovadora e dinâmica? }\end{array}$ & $\begin{array}{l}\text { Tomada de riscos por parte dos empreendedores é uma importante } \\
\text { característica na EF / Capacidade de se reinventar ao enfrentar mudanças } \\
\text { econômicas / Postura empreendedora e dinâmica / Destaque do papel do } \\
\text { empreendedor para identificação e exploração de oportunidades } \\
\text { internacionais. }\end{array}$ & $\begin{array}{l}\text { [Buckley \&. Casson, 2019; Rhenak, } \\
\text { 2018; Zahra, 2018]. }\end{array}$ \\
\hline
\end{tabular}


Apêndice 2: Adicionais e relevantes citações dos entrevistados

\begin{tabular}{|c|c|c|c|}
\hline Empresa & Familiness e Propriedade & Percepção de Risco & Internacionalização \\
\hline A & $\begin{array}{l}\text { "Nós costumamos dizer que não somos uma } \\
\text { empresa familiar, somos uma empresa de } \\
\text { muitas familias. Porque nos privilegiamos a } \\
\text { entrada de pessoas que sejam ligadas a } \\
\text { familiares de membros do time. [...]". Diretor } \\
\text { A } \\
\text { "[...] nós acreditamos que a célula base é a } \\
\text { família. Nós temos hoje nos nossos quadros } \\
\text { praticamente avo, pai e filho, trabalhando } \\
\text { dentro das empresas, e às vezes no mesmo } \\
\text { setor. "Diretor A } \\
\text { "A formação de pessoas é a parte que mais } \\
\text { olhamos. Você quer uma empresa? Forme um } \\
\text { time. Esta é a essência. As pessoas é o nosso } \\
\text { maior patrimônio. "Diretor A } \\
\text { "Falando em empresa familiar, ela tem um } \\
\text { pouco desta característica de 'vamos olhar } \\
\text { para o nosso pessoal, vamos valorizar o nosso } \\
\text { pessoal', o que às vezes não acontece em } \\
\text { grandes corporações onde você busca no } \\
\text { mercado, uma pessoa pronta, ou vai comprar } \\
\text { este conhecimento, esta informação de } \\
\text { outros profissionais. Há o estimulo aqui de se } \\
\text { desenvolver internamente." Gerente A }\end{array}$ & $\begin{array}{l}\text { "Sobre o IDE: Existe uma resistência inicial. Mas o nosso } \\
\text { pessoal já está acostumado à mudança. Nós costumamos } \\
\text { dizer: assumimos qualquer risco, desde que muito bem } \\
\text { dimensionado. E o nosso pessoal no começo era: puxa } \\
\text { vida, mas vaifuncionar? [...] É interessante que as pessoas } \\
\text { quando você faz alguma coisa, no começo ficam assim, } \\
\text { depois 'desnegam'. Agora, se você só fala, aí a resistência } \\
\text { fica." Diretor A } \\
\text { "Não é fácil. Mas não são dificuldades são aprendizados. } \\
\text { Não existem problemas, existem oportunidades não } \\
\text { trabalhadas. É uma forma de enfoque. A grande chave é } \\
\text { fazer disso um projeto de todos e a possibilidade de todos } \\
\text { crescermos juntos. Outra coisa que nos chamou a atenção } \\
\text { é que se você não estiver junto no mercado, você não } \\
\text { cresce". Diretor A } \\
\text { "Nós estamos dispostos e já decidimos isso, que nós } \\
\text { vamos para o mundo. Porque nós queremos as } \\
\text { oportunidades que o mundo oferece. E também sabemos } \\
\text { sobre a concorrência a nível mundial. Quando existe isso, } \\
\text { nós temos a chance de aprimoramento. Isto é muito } \\
\text { importante para qualquer empresa e nós chamamos de se } \\
\text { internacionalizar. A internacionalização é para nós } \\
\text { importante porque além de tudo você aprende e cria } \\
\text { classe mundial nos negócios, nos serviços, nos produtos. } \\
\text { Então isso determinada qualidade. "Diretor A } \\
\text { "A gente tem uma coisa que é 'vai lá e faz'. Nem tudo que } \\
\text { a gente lança está certo, mas, botando em uma balança a } \\
\text { gente acerta mais do que erra. ". Gerente A }\end{array}$ & $\begin{array}{l}\text { Sobre concentração de vendas na América Latina: "[...] se } \\
\text { trata de um produto que, ao ser transportado, ele gera um } \\
\text { grande volume e um baixo valor agregado, então o frete } \\
\text { acaba incidindo muito sobre o custo final do produto para o } \\
\text { consumidor. Como os fretes dentro da América Latina eles } \\
\text { são mais baratos, você acaba tendo uma competitividade } \\
\text { maior dentro desses países." Gerente A } \\
\text { "Os critérios para entrar em um novo negócio ou em outro } \\
\text { tipo de produto, é o seguinte, o mercado tem que ser } \\
\text { atrativo o suficiente em tamanho e potencial de } \\
\text { crescimento. "Diretor A } \\
\text { "A escolha pelos Estados Unidos veio devido ao maior PIB e } \\
\text { a partir dali você consegue fazer mil coisas. Maior mercado, } \\
\text { legislação mais simples, tributação favorável." Diretor A } \\
\text { "Tudo depende de identificar um potencial de mercado, } \\
\text { viabilidade, rentabilidade. Isso é uma coisa que o Diretor A } \\
\text { sempre deixa claro, visar rentabilidade da operação. Não } \\
\text { justifica montar uma distribuidora no Paraguai, pois lá já } \\
\text { tenho } 4 \text { distribuidores e eu vendo muito bem. Mas se eu } \\
\text { identificar que na Europa, Chile, Colômbia, existe um } \\
\text { mercado e eu não estou conseguindo por meio dos players } \\
\text { locais fazer a inserção dos meus produtos, podemos sim } \\
\text { avaliar possibilidades de criar uma estruturafora." Gerente } \\
\text { A }\end{array}$ \\
\hline B & $\begin{array}{l}\text { "A gente tem esta percepção (de } \\
\text { pertencimento). As pessoas que trabalham } \\
\text { aqui, a maioria sempre elogia o ambiente, o } \\
\text { trabalho, diz que fazem parte de uma família, } \\
\text { percebemos uma união. Isso são provas de }\end{array}$ & $\begin{array}{l}\text { "Participando ativamente junto as decisões com os sócios, } \\
\text { claro, por ser uma empresa familiar, existem várias } \\
\text { restrições, ou cuidados extras, para com o patrimônio da } \\
\text { empresa. [...] a aversão ao risco é evidente e a gente tem } \\
\text { que desenvolver um trabalho muito detalhado, muito bem }\end{array}$ & $\begin{array}{l}\text { Sobre o IDE: "Foi um passo importante para reduzirmos os } \\
\text { custos, aumentar a lucratividade. Vale a pena, vamos } \\
\text { continuar." Diretor B } \\
\text { "[...] quando analisamos as possibilidades de } \\
\text { internacionalização, de montar uma plantafora, pensamos }\end{array}$ \\
\hline
\end{tabular}

Internext | São Paulo, v.17, n. 1, p. 22-45, jan./abr. 2022 
que a empresa tem uma cultura mais próxima com os funcionários." Executivo $\mathrm{B}$

"Há uma relação forte entre colaborador e a empresa. [...] o trabalho feito com credibilidade, satisfação, animação, o desempenho é outro. Temos a característica de valorizar os colaborados" Diretor B

"Houve um crescimento muito grande, uma profissionalização. Existe uma preocupação com os irmãos, com a família. Precisamos fazer esta empresa dar dinheiro, porque tem sócio que depende só daqui [...] não podemos errar, precisamos fazer esta empresa dar certo. "Diretor B

"O pai nos cobra muito isso: "Montei uma empresa, quero que vocês vão bem, com união, sem brigas". Estamos trabalhando para ter esta união familiar e perpetuar a geração futura. É um trabalho lento, mas estamos no caminho" Diretor B

"[...] no início muitos familiares atrapalhava um pouco. Alguns tinham formação acadêmica, outros não tinham experiência em nada. Chegou certo momento que sentimos dificuldade na administração. Então conversando com o pai, afastamos aqueles que não estavam preparados. Eles entenderam que foi uma decisão acertada para a empresa. Havia mais dificuldades quando tinham mais membros da família, mais irmãos". Diretor B

"Hoje eu faço esta ponte entre Brasil, Paraguai. [...] poder passar esta realidade para os sócios, isso para mim é outra responsabilidade que traz certa preocupação e trabalho extra. "Executivo B ilustrado de todo passo futuro, todo investimento, de toda exposição ao risco, para que os sócios aceitem ou permitam que se tome determinada ação. "Executivo B

"A maior dificuldade foi o capital próprio. Fizemos uma empresa no Paraguai com tão pouco. [...] evitou-se um custo maior, com capital de terceiros, para maior controle da operação e expansão gradual." Diretor B

"Outra prova da aversão ao risco é que a Empresa B não gosta de tomar empréstimo. Preferem acumular capital e fazer investimentos com capital próprio, do que se expor demais ao risco. Então para mim já é uma vitória muito grande eles terem conseguido captar esta ideia, esta percepção de que realmente a subsidiária no Paraguai é uma oportunidade. "Diretor B

"Para os sócios quando foi aberta esta possibilidade (Paraguai), foi apresentado um pré-projeto, foi um susto não estavam preparados para isso. [...] eles pensavam, se aqui já temos a preocupação de ter domínio do que acontece aqui, imagina como a gente vai controlar, ter domínio, de algo que fica fora do alcance, em outro país, com outras regras, outras leis. "Executivo B

"Hoje posso dizer que eles estão felizes com o investimento, mas passou por um processo de maturação muito grande, de explicações, de várias reuniões, apresentações de cases de sucesso, para que eles chegassem ao consenso de "vai valer a pena, vamos ariscar". Isso eu vejo como uma coisa natural de empresa familiar, esta aversão ao risco, porque sempre vai falar um irmão para o outro, um pai para o filho, sempre um parente para o outro e tem uma responsabilidade maio de responder e correr o risco de fazer uma coisa errada e prejudicar a relação familiar. Porque sai da relação profissional para a relação familiar." Executivo B

"Pela nossa estrutura, uma empresa de pequeno/médio porte, pelo potencial, espaço físico que temos no Paraguai, oportunidades de produtos. Hoje se pensa inicialmente na China. Mas aí esta distância, diferença, tanto geográfica quanto cultural, pesou bastante na nossa avaliação. Quando a gente soube dos benefícios do Paraguai, que poderiam iqualar os custos com a China, claro que a distância geográfica e cultural, por ser uma língua mais próxima da nossa, foi o diferencial." Executivo $B$

"O foco maior foi pela economia tributária, do ganho, da diferença do custo Brasil e do custo Paraguai. A energia 1/4 do valor, a mão de obra bem mais em conta e abundante. $E$ os benefícios de importação/exportação no MERCOSUL e, principalmente, o que mais chamou a atenção foi o projeto Maquila, que só paga 1\% de imposto naquilo que faturado, e 10\% sobre o lucro." Diretor B

"Levou um tempo para nos adaptarmos com o método de trabalho do Paraguai, administração, cultura. Foi importante um crescimento gradativo para conhecer e controlar a nova operação. Pois há bastantes diferenças administrativas e contábeis. Crescimento gradativo foi bem-vindo para aprendermos nesta caminhada. Para depois crescermos sólidos, com informação. "Diretor B 


\begin{tabular}{|l|l|l|l|}
\hline "O Executivo B foi um dos grandes & puramente em expansão na planta do Paraguai. Porque \\
desbravadores. Papel importantíssimo. & nós temos um leque de opções para explorar no Paraguai. \\
"Como vamos reduzir custos? Vamos produzir & Para irmos a outro país hoje não teríamos estrutura \\
aqui, na China? Vamos produzir no Paraguai? & administrativa, financeira, seria um passo longe hoje. & \\
Vocês concordam? " Então foi feito um & "Executivo B & \\
projeto e apresentado à família. É um cara & & \\
que veste a camisa. "Diretor B & & \\
\hline
\end{tabular}

